\title{
USE OF SEISMIC REFRACTION METHOD IN ENVIRONMENTAL GEOPHYSICS
}

\author{
Dr Slobodan Stanic \\ NIS-NAFTAGAS, Geophysical Institute, Batajnicki put 18, 11000 Beograd, Yugoslavia
}

Seismic refraction method is used in environmental geophysics in order to make a precise reconstruction and true interpretation of investigated area. For this, it is neccessary to apply the most modern and very complex procedures and techniques of seismic exploration. One the basic methods within seismic investigations and exploration is seismic refraction method. Without its application it is very difficult to solve problems within geological media, to define precisely investigated area. The method is widely used in environmental geophysics.

In the paper, some domains of application of seismic refraction method in order to solve some environmental problems is presented, as well as systematization of the problems and discussing of some experiences on the method application in environmental geophysics.

Key words: seismics, refraction, ecology, geophysics, exploration, the Earth

\section{INTRODUCTION}

Increasing disdpersion of environmentally contaminated areas in/under the Earth's surface, as well as the growing need for water and constructing on unaccessible terrains, caused a necessity for the better knowledge on geological structure of some investigated terrain. Defining of polluted terrains within the Earth's crust is one of the most important tasks for numerous scientists and experts of various specialties. All of them are giving their efforts to explain different phenomena of environmental geology and solve practical problems of engineering geology, hydrogeology and ecology.

One of the methods within applied geophysics, able to define shallow parts of the Earth's crust, which are the most often areas of constructive and destructive activity of the human being, is, certainly, the seismic refraction method. 


\section{PLACE, ROLE AND WAY OF APPLICATION OF SEISMIC REFRACTION METHOD IN ECOLOGY}

Within environmental-geophysical exploration for solving problems of engineering geology, hydrogeology, civil engineering, urban planning, medicine and a lot of other scientific and technical disciplines, a wide range of geophysical methods is applied. In Table 1, geophysical methods the most often used in environmental geophysics are presented. Their application is possible on/under the Earth's surface, as well as in the subsurface and in boreholes, not only on the land, but also in the water.

Table 1. Applicability of geophysical methods in ecology.

GRAVITY METHOD

GEOMAGNETIC METHOD

SEISMIC METHODS (seismic refraction, seismic reflection, VSP, acoustic seismics)

GEOELECTRIC METHODS (resistivity method, SP, IP, electromagnetic methods:

Turam, TEM, Slingram, MT, VLF)

GPR APPLICATION

GEOTHERMOMETRY

RADIOMETRY

WELL LOGGING

Fact that content, porosity and wetness in rock mass principally influence on propagation velocities of elastic waves, enables a successful application of seismic methods within which, when speaking about exploration of environmental geology, the following methods are applied: seismic refraction, seismic reflection, seismoacoustic and seismic well-logging exploration.

As the most frequent problems within environmental-geological and environmental-geophysical exploration connected to sedimentary areas and depth range from several meters to several hundreds of meters, as a very suitable, seismic refraction method is applied in environmental geology. By its application, boundaries between explored area can be determined. By use of seismic refraction method, defining of lithology and stratigraphy of distinguished geological units, as well as determination of structure and tectonic composition of investigated area, is possible. From a viewpoint of environmental-geological exploration, of particular importance is:

- determination of sedimentary layers depth often presenting a zone of contaminant materials depositing;

- determination of faults and other tectonic disturbances within rocks, along which it is possible to expect intensive tectonic activity, but also front of toxic materials;

-registering big cavities under the terrain surface, filled and ruined old chanels and mineshafts;

- defining elastic parameters, as a real describers of the nature of investigated area. 
Today it is possible to follow, record and analyse seismic waves in frequency range between several $\mathrm{Hz}$ to several thousands $\mathrm{Hz}$. Seismic refraction method is very useful in P- and $\mathrm{S}$ - waves following, which is of great importance for defining parts in the Earth's crust where media saturated with fluids are to be determined. That is very important in distinguishing flows of polluted groundwater in some urban area or in defining unpolluted groundwater flows.

Seismic refraction method is used very often in areas with rough topography, in very complex geological conditions, in boreholes, galleries, tunnels, etc., depending on problem to be solved (Table 2).

Table 2. Ecological problems successfully applied by geophysical methods (Komatina, 1996). Exploration of waste dumps(municipal, industrial, military, hazardous) and former industrial sites (including mining) through the assessment of possible contamination to initial site investigations for waste disposal

Localisation and contouring of dumps

Content of waste dumps

Contamination of the vicinity of waste dumps

Migration of pollutants

Monitoring of contaminated site assessment

Locating damsite leakes before failures occured

Outlining hazardous chemical wastes for subsequent clean-up

Searching for safe repositories for nuclear waste

Basic advantages of seismic refraction method in environmental-geological investigationsare the following:

1. Application of the method makes measurements in the investigated area possible, without experiments on samples or in laboratory.

2. In comparison to the greater number of geological methods, seismic refraction method is more efficient and shorter.

3. By application of the method, 3D view of the terrain is obtained.

4. By the method, data on the observing point, as well as several meters to several hundreds of meters, are obtained.

Some disadvantages of the method are:

1. Impossibility of defining lithology of the investigated area or type of the artificial medium in cases with the same velocities.

2. Impossibility of exploring deep layers and formations, in presence of zone of inverse velocities.

3. In some cases, it is not cost-efficient. 


\section{CONCLUSION}

Environmental-geological exploration, with environmental geophysical ones within, beside great scientific importance, have inevitable great practical significance, in defining serious of problems, from locating abandoned industrial deposits to monitoring polluter migration.

Great importance in defining geological characteristics of terrain in relation to solving present ecological problems, is in domain of the seismic refraction method application.

Of course, seismic refraction method is not universal one, solvind all existent problems of environmental geophysics. In the paper, only possibilities of its application in solving some ecological problems is presented.

Thinking about complexity of ecological, environmental-geological and environmental-geophysical exploration, it may be concluded that only within application of all available geological and geophysical methods of exploration and by detailed comparative analysis of obtained data, it is possible to solve even the most complicated questions within environmental geology and ecology. Contribution of the seismic refraction method in that composition is very important. 